\title{
Comparison of Induction Abortion in the First Trimester Using Misoprostol Alone and Misoprostol With Estrogen Priming
}

\author{
Batool Teimoori $^{\circledR}$, Maryam Esmaeilpoor ${ }^{2}$, Azar Khaefi Ashkezari $^{2}$, Farahnaz Farzaneh $^{3^{*}(\mathbb{D}}$
}

\begin{abstract}
Objectives: Miscarriage is defined as the loss of pregnancy before the 20 weeks of gestational age. This study was conducted to compare the induction abortion in the first trimester using misoprostol alone and misoprostol with estrogen priming. Materials and Methods: This clinical trial was conducted in Ali ibn-e Abitalib hospital of Zahedan in 2017. A total of 100 women with missed abortions under 14 weeks of gestational age were evaluated. The women were randomly assigned into the misoprostol alone and misoprostol with estrogen priming groups. Ultrasound was done to evaluate the presence of remnants 4 hours after the abortion. If it was less than $10 \mathrm{~mm}$, the abortion was considered successful.

Results: The success rate was $38 \%$ in the misoprostol group and $86 \%$ in the misoprostol with estrogen priming group.

Conclusions: Overall, this study showed that estrogen increases the success rate of abortion and reduces the time to abortion.

Keywords: Missed abortion, Misoprostol, Estrogen priming, First trimester
\end{abstract}

\section{Introduction}

Abortion refers to the termination of pregnancy before the 20 weeks of gestational age or under birth weight of 500 $\mathrm{g}(1,2)$. It is estimated that around 40 million abortions occur every year, either legal or illegal, resulting in an abortion rate of $3.5 \%$ (3).

Prostaglandins are the most commonly used drugs which induce abortion in the first and second trimesters of pregnancy. Misoprostol is an analogue of prostaglandin E1 which is prescribed for the prevention and treatment of gastric and duodenal ulcers $(4,5)$. It is also used in obstetrics for the induction of labor, cervical preparation, treatment of postpartum hemorrhage (primary and secondary $\mathrm{PPH}$ ), and induction abortion (6). Unlike other prostaglandins, Misoprostol selectively affects the uterus and cervix and has no adverse effect on the bronchi and blood vessels $(7,8)$.

Regarding the importance of abortion and also considering that studies on the effects of estrogen priming on the success of induction abortion are insignificant, this study comparatively investigated the induction abortion in the first trimester using Misoprostol alone and Misoprostol with estrogen priming.

\section{Materials and Methods}

This clinical trial was conducted in Ali ibn-e Abitalib hospital of Zahedan in 2017. A total of 100 women with missed abortions who had referred to the Gynecology
Clinic of Ali ibn-e Abitalib hospital were studied. Those at the gestational age of 6 to 14 weeks and two ultrasound scans based on the missed abortion were included in the study. While those with the cesarean section history, adrenal disease, renal or hepatic diseases, and prostaglandin allergy were excluded from the study.

Women were randomized to receive misoprostol alone (control group) or misoprostol with estrogen priming (case group). In the misoprostol alone group, the medicine was given at a vaginal dose of $800 \mu \mathrm{g}(4200 \mu \mathrm{g}$ pills) up to 3 times at 8 -hour intervals. The side effects of misoprostol including fever, sweating, fatigue, nausea, vomiting, and abdominal pain, as well as the time to induction abortion were evaluated and recorded. Four hours after the abortion, ultrasound was performed. If the remnants were less $10 \mathrm{~mm}$, a successful abortion was recorded, and if the remnants were greater than $10 \mathrm{~mm}$, the woman would undergo suction curettage.

In the misoprostol with estrogen priming group, the first dose of misoprostol was given to the woman with the oral estradiol valerate $(2 \mathrm{mg})$ and the study was continued similar to the previous group.

The informed consent was obtained from all the participants. The study was approved by the Ethics Committee of Zahedan University of Medical Sciences (Code of Ethics: IR. ZAUMS.REC.1396.9) and also registered in the Iranian Registry of Clinical Trials (identifier: IRCT2017070934981N1; http://en.irct.ir/

Received 9 February 2019, Accepted 24 June 2019, Available online 3 July 2019

${ }^{1}$ Department of Obstetrics and Gynecology, Health Promotion Research Center, School of Medicine, Zahedan University of Medical Sciences, Zahedan, Iran. ${ }^{2}$ School of Medicine, Zahedan University of Medical Sciences, Zahedan, Iran. ${ }^{3}$ Department of Obstetrics and Gynecology, Infectious Diseases and Tropical Medicine Research Center, School of Medicine, Zahedan University of Medical Sciences, Zahedan, Iran. *Corresponding Author: Farahnaz Farzaneh, Email: +989144263014, Email: Farahnaz1826@yahoo.com 
trial/26580).

Data were analyzed in SPSS software version 22.0 using the Chi-square test and Independent T-test.

\section{Results}

In this study, 100 women who had referred to Ali ibn-e Abitalib hospital, Zahedan, for missed abortions were evaluated. The mean patient age, the mean number of pregnancies, and the mean gestational age were $28 \pm 7$ years (minimum 14, maximum 47), $3 \pm 2$ (minimum 1 , maximum 9), and $52 \pm 13$ (minimum 28, maximum 98) days, respectively.

As shown in Table 1, 16 out of 50 women in the control group (32\%) and 42 out of 50 women $(84 \%)$ in the case group had successful abortions. Suction curettage was performed on the rest of women to remove pregnancy remnants.

Both groups were also compared in terms of gravidity, gestational age, causes of termination of pregnancy, and Misoprostol dosage (Table 2).

In terms of gravidity, 25 women were primigravid, while 75 were multigravida. Of the 25 primigravid, 12 women were in the control group and 13 in the case group. Accordingly, out of the 75 multigravida, 38 women belonged to the control group and 37 to the case group. The mean gravidity in the control group was $3 \pm$ 1 (minimum 1 and maximum 9) and in the case group was $3 \pm 2$ (minimum 1 and maximum 7 ). There was no significant difference between the two groups in terms of gravidity.

Regarding the causes of termination of pregnancy, 95 women had missed abortions (50 in the control group and

Table 1. Comparison of Two Groups in Terms of Suction Curettage

\begin{tabular}{lcc}
\hline \multirow{2}{*}{ Group } & \multicolumn{2}{c}{ Suction Curettage } \\
\cline { 2 - 3 } & $\begin{array}{c}\text { Positive } \\
\text { No. (\%) }\end{array}$ & $\begin{array}{c}\text { Negative } \\
\text { No. (\%) }\end{array}$ \\
\hline Misoprostol & $34(68 \%)$ & $16(32 \%)$ \\
Misoprostol + Estrogen Priming & $8(16 \%)$ & $42(84 \%)$ \\
\hline
\end{tabular}

$P$ value $=0.00$.
45 in the case group); 4 abortions were blighted ovum, all of which were from the control group; and 1 abortion was induced abortion which belonged to the control group. Moreover, 34 out of the 50 women with missed abortions in the control group did not have successful abortions and so underwent suction curettage. Likewise, 8 out of the 45 women with missed abortions in the case group did not have successful abortions and underwent suction curettage. Accordingly, 4 cases of blighted ovum and one case of induced abortion successfully aborted the product of pregnancy and did not undergo suction curettage.

In terms of the dosage of misoprostol, 84 women received misoprostol $800 \mu \mathrm{g}$, from which 39 were in the control group and 45 in the case group. In the control group, 7 women needed a second dose and 4 women required a third dose of misoprostol $800 \mu \mathrm{g}$. In the case group, 3 women required a second dose of Misoprostol $800 \mu \mathrm{g}$ and 2 women needed a third dose of Misoprostol. The mean dose of Misoprostol in the control group (400 $\pm 1000)$ and in the case group $(900 \pm 300)$ were not significantly different $(P=0.1)$.

Regarding the gestational age, 44 women were of less than 7 weeks of pregnancy ( 56 days) and 56 women were of above 7 weeks. Of these, 21 women were pregnant for less than 7 weeks and 29 women were pregnant for more than 7 weeks in the control group. While in the case group, 23 women were pregnant for less than 7 weeks, and 27 women were pregnant for more than 7 weeks. The groups were not significantly different in terms of gestational age.

The mean abortion time in the control group was $5 \pm$ 10 hours and in the case group was $4 \pm 8$ hours, which showed a significant difference between two groups $(P=$ 0.038).

No significant side effects were recorded for both groups regarding the consumed drug.

\section{Discussion}

About 40 million abortions per year, either legal or illegal, occur worldwide, resulting in an abortion rate of up to $3.5 \%(9,10)$. Surgical methods including dilatation and curettage (D \& C), dilatation and evacuation (D \& E), and

Table 2. Comparison of Two Groups in Terms of Gravidity, Causes of Termination of Pregnancy, Dosage

\begin{tabular}{|c|c|c|c|c|}
\hline Variables & & Misoprostol & Misoprostol + Estrogen Priming & $P$ Value \\
\hline \multirow{2}{*}{ Gestational age } & $<7$ weeks & 21 & 23 & \multirow{2}{*}{0.95} \\
\hline & $\geq 7$ weeks & 29 & 27 & \\
\hline \multirow{2}{*}{ Gravity } & Primigravid & 12 & 13 & \multirow{2}{*}{0.95} \\
\hline & Multigravida & 38 & 37 & \\
\hline \multirow{3}{*}{ Causes of induced abortion } & Missed abortion & 50 & 45 & \multirow{3}{*}{0.07} \\
\hline & Blighted ovum & - & 4 & \\
\hline & Legal abortion & - & 1 & \\
\hline \multirow{3}{*}{ Dosage of misoprostol } & $800 \mu \mathrm{g}$ & 39 & 45 & \multirow{3}{*}{0.10} \\
\hline & $1600 \mu \mathrm{g}$ & 7 & 3 & \\
\hline & $2400 \mu \mathrm{g}$ & 4 & 2 & \\
\hline
\end{tabular}


suction curettage, even when performed by experienced surgeons (11-13), lead to cervical rupture, uterus perforation, and injury to the abdominal organs. Abortion is an alternative method which has been employed from 30 years ago due to fewer complications and appropriate responses in comparison with surgical procedures $(14,15)$. So far, many studies have been conducted on various types of medical abortion, but few studies have considered the effects of estrogen priming on the success of induction. Therefore, this study aimed to compare the incidence of abortion in the first trimester using misoprostol and misoprostol with estrogen priming.

Our study showed that the success rate of medical abortion in the group using misoprostol alone was only $38 \%$, while the success rate in the group using misoprostol with estrogen priming was $86 \%$; the difference was statistically significant $(P<0.0001)$. The results also displayed that the induction-to-abortion time in the case group was significantly lower than that in the control group $(P=0.049)$. Moreover, no significant difference was observed between the two groups in terms of side effects. In a study conducted by Rudasari et al in Mashhad (20042006) on 100 pregnant women at their first trimester, the effect of Methotrexate and Misoprostol on the success rate of abortion was investigated. It was found that $81(81 \%)$ of the women had successful medical abortion and 19 women underwent suction curettage (16).

In another study by Salari et al conducted in Kerman on 80 women at 13-25 weeks of gestational age, the women were randomly divided into 2 groups receiving either Misoprostol alone or Misoprostol and Laminaria. They reported that time to abortion in the group of misoprostol and Laminaria was significantly shorter than that in the misoprostol alone group and the rate of curettage in the women receiving the combination of two drugs was significantly lower compared to the misoprostol alone group (17).

In a study by Chawdhary et al in 2009, the effect of mifepristone with vaginal misoprostol and misoprostol alone at a gestational age of 63 days or less for the induction abortion was evaluated. It was found that mifepristone with misoprostol increase the success rate of abortion and decrease the complications (18).

In a study by Rezai et al in 2014 on pregnant women in the first trimester of pregnancy, the effect of combination of misoprostol and letrozole was compared with misoprostol alone on the termination of pregnancy. It was observed that complete abortion occurred in 174 women $(81.3 \%)$, from which 84 women $(78.5 \%)$ were in the misoprostol alone group and 90 women $(84.1 \%)$ in the combination group. They eventually concluded that misoprostol alone was as effective as the combination of misoprostol and letrozole (19).

In several other studies, it was seen that the use of estrogen along with other medications significantly increased the success rate of abortion and reduced the time to abortion $(20,21)$. Accordingly, the effect of combination of misoprostol with estrogen priming on the success rate of medical abortion and the improvement of complications was confirmed in this study.

\section{Conclusions}

The results of this study revealed that the success rate of termination of pregnancy in the first trimester was significantly higher in the estrogen priming and misoprostol group compared to the Misoprostol alone group. Moreover, the time to abortion was lower in the group with the combination of 2 drugs. The costeffectiveness of oral single-dose estradiol and shortening the time to abortion was also confirmed in this study. Furthermore, the women's acceptance was highly desirable. It seems that conducting such studies on a wider population, together with the selection of appropriate approaches could lead to a detailed planning for better health interventions.

\section{Conflict of Interests}

Authors declare that they have no conflict of interests.

\section{Ethical Issues}

This study was part of a dissertation which was approved by the Ethics Committee of Zahedan University of Medical Sciences in 2016 (Code of Ethics: IR. ZAUMS. REC.1396.9).

\section{Financial Support}

No financial support was obtained from any organization or university.

\section{Acknowledgments}

The sincerest thanks of authors go to all the distinguished professors, colleagues, and women who collaborated in the implementation of this project.

\section{References}

1. Cunningham F, Leveno K, Bloom S, Spong CY, Dashe J. Williams obstetrics. 24th ed. McGraw-Hill; 2014.

2. Jones HW, Rock JA. Te Linde's Operative Gynecology. Lippincott Williams \& Wilkins; 2015.

3. Sedgh G, Bearak J, Singh S, et al. Abortion incidence between 1990 and 2014: global, regional, and subregional levels and trends. Lancet. 2016;388(10041):258-67.

4. Honkanen H, Piaggio G, Von Hertzen H, et al. WHO multinational study of three misoprostol regimens after mifepristone for early medical abortion. II: Side effects and women's perceptions. BJOG. 2004;111(7):715-25.

5. Paul ME, Mitchell CM, Rogers AJ, Fox MC, Lackie EG. Early surgical abortion: efficacy and safety. Am J Obstet Gynecol. 2002;187(2):407-11.

6. Creinin MD. Medical abortion regimens: historical context and overview. Am J Obstet Gynecol. 2000;183(2):S3-S9.

7. Wu HL, Marwah S, Wang P, Wang QM, Chen XW. Misoprostol for medical treatment of missed abortion: a systematic review and network meta-analysis. Sci Rep. 
2017;7(1):1664.

8. Rostom A, Dube C, Wells GA, et al. Prevention of NSAIDinduced gastroduodenal ulcers. Cochrane Database Syst Rev. 2002;(4):CD002296. doi:10.1002/14651858.CD002296

9. Nuutila M, Toivonen J, Ylikorkala O, Halmesmäki E. A comparison between two doses of intravaginal misoprostol and gemeprost for induction of second-trimester abortion. Obstet Gynecol. 1997;90(6):896-900.

10. Hawkey CJ, Karrasch JA, Szczepanski L, et al. Omeprazole compared with misoprostol for ulcers associated with nonsteroidal antiinflammatory drugs. $\mathrm{N}$ Engl J Med. 1998;338(11):727-34.

11. Allen R, O'Brien BM. Uses of misoprostol in obstetrics and gynecology. Rev Obstet Gynecol. 2009;2(3):159.

12. Goldberg AB, Greenberg MB, Darney PD. Misoprostol and pregnancy. N Engl J Med. 2001;344(1):38-47.

13. Ricciotti E, Fitz Gerald GA. Prostaglandins and inflammation. Arterioscler Thromb Vasc Biol. 2011;31(5):986-1000. doi: 10.1161/ATVBAHA.110.207449

14. Bani S, Hasanpour S, Jalali S, Ebrahimi H, Mamaghan M. Leiomyoma and nutrition, a case-control study. Int J Womens Health Reprod Sci 2013;1(1):5-13. doi: 10.15296/ ijwhr.2013.02.

15. Scheepers H, Van Erp E, Van den Bergh A. Use of misoprostol in first and second trimester abortion: a review. Obstet Gynecol Surv. 1999;54(9):592-600.

16. Forghani F, Mehdizadeh Kashi A, Sadegi K, Kaveh M,
Ghaffari M. Uterine Leiomyosarcoma: A Case Report. Int J Womens Health Reprod Sci. 2018;6(2):223-225. doi: 10.15296/ijwhr.2018.38

17. Salari Z, Sharifi L, Aali B. Comparison of vaginal misoprostol alone and vaginal misoprostol with laminaria in abortion induction of second trimester. Journal of Kerman University of Medical Sciences. 2012;19(2):160162

18. Chawdhary R, Rana A, Pradhan N. Mifepristone plus vaginal misoprostol vs vaginal misoprostol alone for medical abortion in gestation 63 days or less in Nepalese women: A quasi-randomized controlled trial. J Obstet Gynaecol Res. 2009 Feb;35(1):78-85. doi: 10.1111/j.14470756.2008.00864.x.

19. Rezai Z, Bazardehi H, Sareh S, Ghasemi Nezhad A, Saeid Sadeghi A, Ghorbani Yekta B. Letrozole and misoprostol versus misoprostol alone for termination of pregnancy: a randomized clinical trial. Tehran University Medical Journal. 2014;71(11).

20. Farzaneh F, Tavakkoli Z, Soleimanzadeh SH. Assessment of occurrence of preeclampsia and some clinical and demographic risk factors in Zahedan city in 2017. Clin Exp Hypertens. 2018. doi: 10.1080/10641963.2018.1523919

21. Razavi M, Rashidi F, Jafari F, Farzaneh F, Sarghozaei $\mathrm{N}$. The role of uterine artery doppler ultrasound in the second trimester in predicting preeclampsia. Int J Pediatr. 2019;78(5):9405-9411. doi: 10.22038/IJP.2019.37066.3229

(c) 2019 The Author (s); This is an open-access article distributed under the terms of the Creative Commons Attribution License (http://creativecommons.org/licenses/by/4.0), which permits unrestricted use, distribution, and reproduction in any medium, provided the original work is properly cited. 